\title{
Chapter 1 \\ The Role of Indicators in Integrating Process of Sustainability into Corporate Activities: Case Studies of Japanese Companies
}

\author{
Hirotsugu Kitada* and Katsuhiko Kokubu ${ }^{\dagger}$ \\ *Faculty of Business Administration \\ Hosei University, Chiyoda, Tokyo, Japan \\ ${ }^{\dagger}$ Graduate School of Business Administration \\ Kobe University, Kobe, Hyogo Prefective, Japan
}

\section{Introduction}

Amid an increase in information disclosure processes that consider the views of investors, companies have been embedding sustainability into their business. Rather than just reporting on the relation between sustainability and business activities, firms have also been using key performance indicators (KPIs) to report on targets and results. Decisions on the kind of management indicators selected and the kind of criteria used to select management targets are linked to the kind of relationship the company seeks to build with its society and environment.

At the strategic level — such as in external reporting — attempts have been made to integrate sustainability into corporate activities, but translating this into organizational activities requires further integration at the management system level (Gond et al., 2012). In this process, the use of 
KPIs is expected to play an important role within management systems. As well as being the foundation of management control systems (MCS), KPIs are expected to play a role in external reporting.

However, studies suggest that sustainability indicators are not used in a uniform manner. When management systems use indicators for environmental control, improvements in environmental performance have indirect impacts on economic performance (Henri \& Jounault, 2010), and the use of indicators may promote the integration process. On the other hand, these frameworks also reflect the demands of external stakeholders in organizational activities (Rodrigue, Magnan \& Boulianne, 2013), regulate the organization's internal and external boundaries (Bouten \& Hoozee, 2013), and acknowledge social responsibility.

Sustainability indicators thus have a multifaceted nature. Against this background, this study investigates the role of indicators in integration management processes. Specifically, we use case studies on three Japanese companies to analyze each of their management processes.

Our findings are as follows. First, regarding the integration of sustainability into corporate activities, some companies focus on indicatorbased control while others prioritize control through their organizational culture. While their objective (i.e., integration) may be the same, companies use different approaches. Second, differences in the approach to management control influence how the demands of stakeholders particularly investors and rating agencies — are received. Third, the roles environmental control indicators play in the integration process differ depending on which stakeholders are prioritized in the sustainability strategy.

Through these analyses, this study makes two important contributions to the literature. First, it provides a comparative study of companies applying different sustainability management approaches to attain the same integration goal. Second, it shows that indicators are used in different ways depending on whether the interaction between the environment and economics is understood in relation to capital markets or to product markets.

The rest of this chapter is structured as follows. Section 2 reviews the literature to locate the study within the current research. Section 3 describes the study's methodology. Case study analyses are provided in 
Section 4. The case studies are discussed in Section 5. Finally, Section 6 concludes the chapter.

\section{MCS and Integration Management}

Recent studies have shown that, when management systems use indicators for environmental control, improvements in environmental performance have indirect impacts on economic performance (e.g., Henri \& Journeault, 2010; Henri, Boiral \& Roy, 2014). These studies have also shown that the use of systems for environmental control does not have a direct impact on the economic performance. This suggests that companies can link the environment and economics by using management systems based on sustainability indicators, and thereby improve their performance.

A rich body of work in the fields of strategy and business administration has been accumulated concerning the relation between corporate social responsibility (CSR) activities and financial performance. A meta-analysis of these studies shows a positive correlation between the two (e.g., Orlitzky, Schmidt \& Rynes, 2003). However, not all companies are able to link their CSR activities to financial performance, and companies that have the ability differ in their capacity to do so (Barnett \& Salomon, 2012). One important competence is environmental management control. Since its effectiveness is context-dependent, it is important to clarify the mechanisms by which indicators link the environment to economics.

Further, internal sustainable management efforts tend to be less advanced than external information disclosure efforts, which has a negative impact on investors' evaluations (Hawn \& Ioannou, 2016). Amid the growing influence of investors on sustainability activities through integrated reporting, the kind of influence their demands have on internal management is also an important question.

The selection and use of sustainability indicators also function to incorporate social demands into the organization. Establishing environmental management indicators clearly defines stakeholders' demands and engages with them within the organization (Rodrigue, Magnan \& Boulianne, 2013). While external reporting and indicator-based internal management influence each other, they also promote and restrict sustainability 
activities (Bouten \& Hoozee, 2013). Therefore, an analysis of the role of indicators in the integration process needs to take into account the role of indicators in mediating social issues.

\section{Materials and Methods}

We conducted interviews with three Japanese companies (who are pseudonymous in this study) to discover how indicators are used within their integration management processes. The cases were selected based on the book by Yin (2003). To analyze the companies' role within integration management processes, we selected companies that had clear environmental elements within their corporate strategy and that had sought to contribute to sustainability through their products and services.

An overview of each of the companies is provided in Table 1. The companies operate in the manufacturing sector. Our interviewees included not only staff in the environmental department but also managers in the finance and corporate planning departments. The interviews were recorded and transcribed. Where necessary, we also refer to internal and public materials, such as lists of the control indicators in use.

Table 1. List of interviewees.

\begin{tabular}{|c|c|c|}
\hline $\begin{array}{l}\text { Name of } \\
\text { corporation }\end{array}$ & Industry & Interviewee \\
\hline Alpha & $\begin{array}{l}\text { Precision } \\
\quad \text { manufacturing }\end{array}$ & $\begin{array}{l}\text { - Manager for social and environmental issues } \\
\text { - Staff in the social and environmental department } \\
\text { - CSR manager } \\
\text { - PR manager }\end{array}$ \\
\hline Beta & Machine tools & $\begin{array}{l}\text { - High-level manager in the corporate planning } \\
\text { department } \\
\text { - High-level CSR manager } \\
\text { - Staff in the corporate communication department }\end{array}$ \\
\hline Gamma & $\begin{array}{l}\text { Housing } \\
\text { manufacturing }\end{array}$ & $\begin{array}{l}\text { - } \text { CFO } \\
\text { - CSR officer } \\
\text { - High-level environmental manager } \\
\text { - High-level PR manager }\end{array}$ \\
\hline
\end{tabular}




\section{Case Study Analysis}

\subsection{Alpha case study}

Alpha company is engaged in several business areas, such as multifunction devices, healthcare devices, and industrial materials. It recognizes the role of sustainable management in increasing sales, reducing costs, and raising brand value. It therefore values $\mathrm{CDP}$ and other rating agencies, indexes, and external commendations. Alpha has a high level of CSR orientation and takes a proactive approach to sustainable management.

Examples of the strategic elements of Alpha's engagement with sustainable management include its green products, green marketing, and green factory. It also proactively uses non-financial indicators to promote integration management in each of these processes. Let us now analyze the issue from the perspective of products and business processes.

First, in its product-related activities, Alpha sets out numerical targets for the proportion of sales represented by green products, which are managed at the level of management control. At the strategic level, the corresponding indicators are incorporated into the firm's environmental management targets and are reported externally. In other words, Alpha's use of indicators has produced an interaction between the environment and economics. In its actual operations, Alpha has developed certification standards for its green products, which are reflected in its product development.

However, Alpha has not been able to clearly sketch out the relation between green products and profitability. Rather, these indicators have been used to respond to demands from external rating agencies, and efforts to promote integration have been informed by the views of their stakeholders. In this sense, it could be argued that Alpha's integration between sustainability and corporate activities at the product level has a high level of CSR orientation.

Second, in its business processes, Alpha has attempted to integrate sustainability with its corporate activities through optimization. Through its green marketing, it promotes environment-friendly activities in its logistics, packaging, sales, and services; in its green factories, it evaluates and certifies the environmental impact of its production sites. These activities both aim to reduce the company's environmental burden while cutting costs by making their processes more efficient. 
At the management control level, these activities are, by definition, elements of cost management, and their environmental contribution is limited to calculating and reporting on the results afterward. Since environmental management has traditionally been associated with additional costs for the company, Alpha has been able to change its mind-set by emphasizing the costs that can be saved by optimizing the use of resources and energy conservation. However, since it is difficult to separate cost-cutting due to environmental measures from other cost reductions from the outset, the environmental contribution ends up being evaluated after the event.

\subsection{Beta case study}

Beta company is engaged in a range of business activities involving agricultural machinery, engines, construction machinery, water treatment facilities, and other markets. It began to make proactive environmental efforts at an early stage in the 1990s. Since its products are in areas closely related to social and environmental issues, such as water, agriculture, and energy, the company recognized the relation between improving and selling its products and solutions to local and social issues.

For example, manufacturing and selling agricultural machinery in Thailand, Vietnam, and other parts of Southeast Asia was understood to improve local productivity as well as generate employment and contribute significantly to sustainable development. In recent years, economic development and urban migration in Southeast Asia have led to the modernization of agriculture and a greater need for machinery and equipment. Beta's products promote more efficient food productivity, and responding to customer needs is also seen as contributing to solving social issues.

The intersection between business activities generated through products and services and sustainability is easy to break down into strategies and operations. Thus, Beta uses ordinary financial indicators rather than setting out special indicators for integration management at the management control level. However, to complement its indicator-based MCS, Beta incorporates environmental considerations into its organizational culture and other informal management frameworks. 
Beta deals in a range of products, such as agricultural machinery, engines, construction machinery, and water treatment facilities. Its customers thus vary widely, from individual farmers to construction and automobile businesses, to the government, each relying on different commercial practices, contract terms, and product life cycles. Various organizational cultures have therefore been formed at each site. Given this state of affairs, Beta has been reluctant to apply non-financial indicators for its company-wide management.

On the other hand, its internal management places importance on developing interpersonal networks, with the organizational culture positioned as underpinning human relations. The emphasis on the cultural aspects of organizational control is also applied to sustainable management. Rather than using indicators to manage the environment or society, such approaches are reflected in the culture of the organization.

\subsection{Gamma case study}

gamma company operates in the housing sector. It began to record a deficit during the 2008 financial crisis, but its subsequent strategies have come to recognize the importance of an environmental strategy. The environmental impact of Gamma's products appeals to its highly educated customers, and efficient utility costs and its eligibility for government subsidies also help differentiate it from other companies. Customer needs have thus influenced the direction of its integration management, with Gamma developing strongly customer-oriented eco-products.

Being able to link products and services to social or environmental issues makes it easier for a company to try to integrate sustainability and corporate activities at the strategic level. Gamma's environment-friendly homes have received much attention since the change in social attitudes to renewable energy occurred following the 2011 earthquake and tsunami. Traditionally, Gamma has provided high-quality housing at high prices, targeting highly educated, high-earning customers. This customer bracket is particularly sensitive to environmental issues, which makes Gamma's products a good match for their needs. Gamma's environment-friendly housing accounts for at least $80 \%$ of sales. 
Gamma also started using solar power and Ene-Farm in its environmentfriendly housing before other companies and has been able to receive government subsidies on terms more favorable than those its competitor products have been offered. In this sense, rather than being oriented simply toward realizing economic and environmental factors through its products, Gamma has incorporated the environment into its development and commercialization processes as a way of differentiating itself from its competitors. These products are difficult for other companies to copy and form into a sustainable core competence (Chen, 2008), enabling Gamma to use its product image and government projects to differentiate itself from other companies to generate a competitive edge.

Because Gamma has integrated the environment and corporate activities at the product and strategic levels in this way, it uses ordinary financial information for management control purposes. Like Beta, Gamma emphasizes the embedding of a sustainability approach within its organizational culture.

However, Gamma does not use non-financial environmental indicators to promote the integration between business and sustainability. Gamma eliminated the environmental elements that lack customer appeal from its strongly customer-oriented integration management. Biodiversity is a representative example of such a category. Unlike energy conservation at home, burdening the consumer with additional costs would not necessarily contribute significantly to differences in quality or function.

Gama uses non-financial indicators to manage these factors. Instead of promoting integration between the product and strategic management, Gamma controls other environmental elements that appeal to investors and other stakeholders. These indicators complement Gamma's sustainability management by covering non-profitable aspects of environmental concerns.

\section{Discussion}

This study was designed to investigate the role of indicators in integration management processes. Specifically, we use case studies of three Japanese companies to analyze each of their management processes. The findings yield valuable insights into the effects of using sustainability indicators in combination with social, environmental, and economic activities. 
First, among the processes applied within the three companies to integrate sustainability into their corporate activities, some have focused on indicator-based control and others have focused on control through their organizational culture. While their aim (i.e., integration) might be the same, the companies use different approaches. The companies differ in their capacity to link their CSR performance to financial performance (Barnett \& Salomon, 2012), and this difference in competence also influences how effectively the indicators are used in the integration process. Alpha, recognizing that its products do not contribute to sustainability as such, developed non-financial indicators related to sustainability and oriented its organizational activities along these lines. By contrast, Beta and Gamma were aware that the environment was integrated into their corporate activities at both the product and strategic levels, which enabled them to manage their organizations through an MCS comprising ordinary financial indicators. Incorporating sustainability into their informal systems, such as in their company's vision and culture, also complemented the use of these indicators (Epstein, Buhovac \& Yuthas, 2015).

Second, differences in management control also impact how the demands of investors and rating agencies are received. Establishing and reporting on internal management systems relating to sustainability activities generate useful information from the point of view of investors and rating agencies (Hawn \& Ioannou, 2016). Alpha developed an ecoproduct certification system to reflect the demands of investors and rating agencies, promoting the integration of the environment with corporate activities at the product level. It then used indicators to control its progress and disclosed the information externally. As accountability in external information disclosure was consistent with accountability for internal management purposes, the company was able to build on this link to advance its sustainability activities.

For Beta and Gamma, on the other hand, the aim of externally disclosing non-financial information was to take into account the demands of investors and rating agencies and then legitimatize their organization. However, this was decoupled from their internal integration management. With the environment and economics integrated at the product and strategic levels, Beta and Gamma designed their management systems in relation to their customers. Thus, their accountability frameworks for 
information disclosure to investors were not necessarily consistent with their internal management frameworks.

Third, our findings suggest that the role of environmental control indicators in the integration process differs depending on which stakeholders are prioritized in the sustainability strategy. Henri and Journeault (2010) showed that the use of environmental control indicators had an impact on business results through improved environmental performance. As our case studies show, however, indicator-based control is effective in integration process when sustainability management systems take into account the views of investors, but the use of indicators is not necessarily effective when customers are the focus; in such a case, the alternative - whereby control is based on organizational culture — has a greater effect.

Beta and Gamma took customer needs into account in their sustainability management. For these companies, the role of sustainability indicators was to complement the sustainability elements that tended to be neglected in their product development. When sustainability is promoted within product development, the latter concept often takes priority, and any environmental elements that do not fit tend to be neglected. External stakeholders therefore need to be the judge of whether the content of activities and standards are socially appropriate. Sustainability indicators that are disconnected from the integration process can still function effectively in processes that incorporate the demands of stakeholders (Rodrigue, Magnan \& Boulianne, 2013).

Using sustainability indicators as control indicators and determining targets serve to incorporate external perspectives into the organization (Rodrigue, Magnan \& Boulianne, 2013; Bouten \& Hoozee, 2013; Contrafatto \& Burns, 2013). However, management based on these indicators can generate conflict between economics and the environment, particularly in the short term. The use of indicators can thus also restrict corporate activities (Burns \& Stalker, 1961).

\section{Conclusion}

This chapter reports on three case studies of Japanese companies. We analyzed their integration management processes and investigated the role of indicators. We focused on the use of indicators in the integration process and report several findings. First, in integrating sustainability into their corporate activities, some companies focus on indicator-based controls, 
while others prioritize control through their organizational culture. While their purpose (i.e., integration) is the same, companies use different approaches. Second, the differing approaches to management control impact how stakeholder demands - particularly demands from investors and rating agencies - are received. Third, the role that indicators play in environmental control in the integration process differs depending on how the firm prioritizes its stakeholders in its sustainability strategy.

Through these analyses, this chapter makes two contributions to the literature. First, it provides a comparative study of companies that apply different sustainability management approaches to attain the same integration goal. Second, it shows that companies use indicators differently, depending on whether they understand the interaction between the environment and economics in relation to capital markets or product markets.

Our findings, particularly the evidence on the differences in integration process depending on stakeholder prioritization, have implications for sustainability managers who design the MCS for companies to achieve their sustainability strategies. Furthermore, our evidence is important for rating agencies that focus on sustainability issues, as they concentrate on evaluating the corporate internal management capability to assess sustainability performance. Although these assessments mainly address formal sustainability management systems, some companies can integrate sustainable development using mainly informal management systems, such as the cultural aspects of organizational controls.

\section{Acknowledgments}

This work was supported by JSPS KAKENHI Grant Numbers JP18H03824, JP16H03679, and JP18K12902.

\section{References}

Barnett, M. L. and Salomon, R. M. (2012). Does it pay to be really good? Addressing the shape of the relationship between social and financial performance. Strategic Management Journal 33(11), 1304-1320.

Burns, T. E. and Stalker, G. M. (1961). The Management of Innovation. Rochester, NY: Social Science Research Network. 
Bouten, L. and Hoozée, S. (2013). On the interplay between environmental reporting and management accounting change. Management Accounting Research 24(4), 333-348.

Chen, Y. S. (2008). The driver of green innovation and green image-green core competence. Journal of Business Ethics 81(3), 531-543.

Gond, J. P., Grubnic, S., Herzig, C. and Moon, J. (2012). Configuring management control systems: Theorizing the integration of strategy and sustainability. Management Accounting Research 23(3), 205-223.

Epstein, M. J., Buhovac, A. R. and Yuthas, K. (2015). Managing social, environmental and financial performance simultaneously. Long Range Planning 48(1), 35-45.

Henri, J. F. and Journeault, M. (2010). Eco-control: The influence of management control systems on environmental and economic performance. Accounting, Organizations and Society 35(1), 63-80.

Henri, J. F., Boiral, O. and Roy, M. J. (2014). The tracking of environmental costs: Motivations and impacts. European Accounting Review 23(4), 647-669.

Hawn, O. and Ioannou, I. (2016). Mind the gap: The interplay between external and internal actions in the case of corporate social responsibility. Strategic Management Journal 37(13), 2569-2588.

Orlitzky, M., Schmidt, F. L. and Rynes, S. L. (2003). Corporate social and financial performance: A meta-analysis. Organization Studies 24(3), 403-441.

Rodrigue, M., Magnan, M. and Boulianne, E. (2013). Stakeholders' influence on environmental strategy and performance indicators: A managerial perspective. Management Accounting Research 24(4), 301-316.

Yin, R. K. (2003). Applications of Case Study Research, 4th edn. Applied Social Research Methods. Thousand Oaks: Sage Publications. 